\title{
Para conhecer: \\ Semântica, de Ana Quadros Gomes e Luciana Sanchez Mendes
}

Fernanda Rosa Silva

Pós-doutoranda do GEPEX. Universidade Federal Fluminense. E-mail: fernandarosa2006@yahoo.com.br

Resenha do livro:

GOMES, A. Q.; SANCHEZ-MENDES, L. Para conhecer: Semântica. São Paulo: Contexto, 2018.

\section{Organização e proposta da obra}

O livro intitulado Para conhecer: Semântica é uma obra introdutória, destinada, principalmente, a estudantes das faculdades de Letras do Brasil. Nele, são apresentadas, de forma objetiva e de fácil entendimento, as ferramentas básicas e fundamentais para compreensão e apropriação da Semântica Formal: o campo da linguística que explora o significado de uma língua com base em um aparato lógico-matemático

A obra compõe uma coleção lançada pela editora Contexto, da qual fazem parte mais quatro volumes que, segundo a editora, foram escritos por especialistas na área, com o objetivo de apresentar, em uma linguagem acessível, as propostas introdutórias de cada um dos temas de investigação. O volume sobre Semântica não é diferente. Foi escrito por duas autoras altamente qualificadas na área: Luciana Sanchez Mendes (UFF) e Ana Quadros Gomes (UFRJ). Ambas possuem ampla formação em Semântica Formal, obtida no Brasil e no exterior, e desenvolvem pesquisas concentradas nesse campo de análise linguística. Possuem várias publicações com temas concernentes à Semântica e atuam como professoras em universidades renomadas no Brasil. 
Como já mencionado, esse volume tem como objetivo principal traduzir conceitos, muitas vezes considerados complexos, para uma linguagem acessível, de maneira que um estudante iniciante na graduação consiga dominá-los. É organizado em quatro capítulos, formato já definido pela coleção. O capítulo 1 delimita o objeto de investigação da Semântica Formal no universo de estudos do significado de uma língua. O capítulo 2 é reservado para discutir e analisar os conceitos concernentes ao sintagma nominal. O capítulo 3, por sua vez, apresenta as questões pertinentes à semântica do sintagma verbal. Por fim, o capítulo 4 discute as noções relacionadas a modificadores na língua, como adjetivos e advérbios.

Entre os muitos diferenciais desta obra, considerando outros manuais de semântica disponíveis no mercado brasileiro, podemos destacar o fato de que as autoras buscaram explorar os conceitos fundamentais da Semântica Formal, sempre lançando mão de explicações com dados do português brasileiro, doravante $\mathrm{PB}$, o que torna conceitos complexos mais facilmente compreensíveis para iniciantes. Além disso, ressalta-se a inclusão de um capítulo exclusivo para "Modificação", em que se abordam questões relacionadas a advérbios e a adjetivos, muitas vezes considerados pelas gramáticas tradicionais como termos acessórios e não discutidos nos manuais de semântica já existentes.

Destacamos, também, que a organização da obra facilita a compreensão do leitor. Para cada capítulo, as autoras apresentam seu objetivo geral, além de descreverem o objetivo de cada seção que será tratada no respectivo capítulo. Os dados em português brasileiro, conforme já mencionado, além de diversas ilustrações, como a do reticulado (GOMES; SANCHEZ-MENDES, 2018, p. 66), auxiliam grandemente na elucidação de conceitos muitas vezes abstratos. Além disso, há um breve resumo ao final de cada capítulo, seguido de exercícios que auxiliam na para a fixação dos conceitos. Dada a sua característica bastante didática, essa obra será de bastante importância para a compreensão e a adesão de mais pesquisadores ao campo da investigação científica do significado, um campo que ainda carece de exploração mais aprofundada. 


\section{Os capítulos da obra}

O capítulo 1 apresenta os conceitos mais gerais e fundamentais da Semântica Formal. Há uma preocupação em delimitar o objeto de estudo dessa ciência, distinguindo-a das demais ciências linguísticas que investigam o significado. As autoras discutem a dificuldade em conceituar significado e destacam que a Semântica Formal busca investigar o significado da sentença com apoio de ferramentas lógico-matemáticas. Conceitos básicos da Semântica Formal como anomalia, ambiguidade, nexos lógicos, sentido e referência, e saturação de predicado são apresentados de forma clara e sucinta ao leitor.

Os estudos de análise semântica, como enfatizado pelas autoras, trazem a exploração do significado como objeto principal da investigação científica. Em especial, a Semântica Formal, abordagem adotada pela obra, tem contribuído com a investigação do significado não somente em relação a línguas europeias amplamente descritas, mas também na descrição e na explicação do PB e de diversas línguas sub-representadas, como as línguas indígenas.

A Semântica Formal diferencia-se das outras abordagens de investigação do significado primeiramente por buscar a explicação do significado da sentença, considerando a sua composicionalidade, e, em segundo lugar, por fazer uso de uma metalinguagem lógico-matemática, emprestada de diversos lógicos e filósofos investigadores da linguagem. Essa abordagem apresenta uma proposta verifuncional do significado, na qual são consideradas as condições de verdade de uma sentença. Assim, segundo a Semântica Formal, saber o significado de uma sentença é saber as condições no mundo em que ela será verdadeira ou falsa. Como bem ilustrado pelas autoras: "saber o significado de uma sentença é saber identificar os cenários em que ela pode ser utilizada" (GOMES; SANCHEZ-MENDES, 2018, p. 16).

Para explicar o significado das sentenças, o livro assevera que a Semântica Formal adota a Lógica e a Filosofia Analítica e toma como essenciais ideias de pensadores como Frege, 1892 e Russell, 1905 que buscaram, no funcionamento das línguas naturais, as explicações lógicas e filosóficas de suas questões de investigação. Além de tomar a Lógica e a Filosofia como ponto de partida para o estudo do significado das línguas, 
as autoras ainda alertam que a Semântica Formal também se aproxima da teoria gerativa, porque leva em consideração a competência semântica do falante. Também busca explicar o significado da sentença por meio de suas partes, ou seja, de sua composição sintática, questões que estão estritamente ligadas a noções como recursividade e composicionalidade.

Um dos conceitos discutidos no capítulo é o de ambiguidade, definida, de forma geral, como duplicidade de sentidos. Pode ocorrer no nível lexical, sintático e nas relações de escopo entre os elementos da sentença. Outros conceitos importantes explorados no texto são: 1) os nexos lógicos, as relações lógicas que podem ocorrem entre sentenças declarativas das línguas naturais; 2) acarretamento, que trata da relação entre a verdade de duas sentenças; 3) contradição, uma relação na qual quando uma sentença A é verdadeira, a sentença B é necessariamente falsa; 4) contingência, segundo o qual duas sentenças podem ser verdadeiras, a depender das condições de mundo. Também é abordado o conceito de pressuposição, segundo o qual há informações atreladas a uma construção ou expressão e essas informações são tomadas como verdadeiras pelo falante e pelo ouvinte. "O conteúdo pressuposicional é visto como conhecimento compartilhado entre o falante e seu ouvinte." (GOMES; SANCHEZ-MENDES, 2018, p. 36).

No que diz respeito à discussão de 'significado', as autoras apresentam brevemente a proposta clássica de Frege, formulada originalmente em 1892. O filósofo propõe uma divisão do conceito de 'significado' em dois: sentido e referência. Para Frege, a referência diz respeito ao objeto no mundo, enquanto o sentido é a forma como esse objeto é descrito. Dessa maneira, um mesmo objeto, ou uma mesma referência, pode apresentar diversos sentidos. É o caso do exemplo clássico de Frege da Estrela da Manhã e Estrela da Tarde. Essas expressões descrevem sentidos distintos para um mesmo planeta, Vênus, isto é, uma mesma referência. Tal reflexão fregeana mantém-se nas pesquisas mais recentes sobre investigação do significado a partir de sua referência no mundo.

Por fim, são apresentados mais dois conceitos essenciais: predicação e composicionalidade. A predicação é explorada a partir do conceito de saturação, vindo também das reflexões de Frege. Como bem se ilustra no volume, uma expressão é saturada quando é completa de significado, ao passo que uma 
expressão não saturada, por outro lado, carece de informações para ser completa. Um predicado é uma expressão não saturada, enquanto uma sentença consiste em uma expressão saturada. Dessa maneira, o significado de uma sentença é um processo de saturação de suas partes e depende da composicionalidade destas.

O capítulo 2 é reservado para explorar o sintagma nominal, seus diversos tipos e as propriedades semânticas de cada um. São abordados temas como: nome nu, determinante, distinção massivo-contável, pluralidade e indefinitude. Além disso, são expostas as teorias clássicas e as ferramentas da Semântica Formal para a análise desses fenômenos.

Determinante, para as autoras, são "palavras funcionais que realizam operações no domínio dos nomes comuns" (GOMES; SANCHEZ-MENDES, 2018, p. 59). São exemplos de determinantes em português: 'o', 'os', 'um', 'alguns'. Esses são funções que tomam um nome comum como argumento para fazer referência a um indivíduo no mundo.

Quanto aos nominais nus, são esses nomes comuns que ocorrem sem a presença de um determinante, por exemplo: "Homem não chora." (GOMES; SANCHEZ-MENDES, 2018, p. 61). Esse assunto é, no livro, amplamente explorado, sobretudo com base em dados do PB, já que tal fenômeno em nossa língua se distingue do que ocorre em outras, como o inglês e o próprio português europeu. Há diversas propostas para descrever a semântica dos nominais nus, conforme indicam as autoras. Na obra, são apresentadas rapidamente as propostas de Carlson (1977) e de Chierquia (1998). Ambos defendem que nominais nus denotam espécies. Sendo assim, no exemplo acima, o significado da sentença é que a espécie 'homem', em geral, possui a propriedade de não chorar.

Em relação à semântica do plural, as autoras apresentam a proposta clássica de Link (1983), na qual o domínio nominal tem uma estrutura interna. Ou seja, o autor defende que os sintagmas nominais possuem, além de unidades, partes de unidades em sua estrutura. Uma sentença como "Comprei abacaxi" (GOMES; SANCHEZ-MENDES, 2018, p. 62) pode significar singular, plural, ou até partes da fruta. Link apresenta a relação lógica entre as partes e o todo, chamada de mereologia. Essa relação pode ser representada por um reticulado, 
que ilustra as possíveis combinações de partes para formar um todo. O reticulado contém átomos, que são as unidades singulares, e as somas desses átomos representam o plural. Um exemplo dessa natureza é claramente ilustrado na obra na página 66 (GOMES; SANCHEZ-MENDES, 2018).

A obra esclarece que a distinção massivo-contável também não se dá de maneira uniforme nas línguas. Uma distinção geral seria que nomes contáveis podem ser individuados, possuem cardinalidade, e nomes massivos não. Entretanto, como se explora no livro, essa distinção não é tão clara e varia de língua para língua. Abordagens ontológicas, que tomam como referência o objeto no mundo, não são as melhores para explicar essa distinção. Por outro lado, propostas puramente semânticas ou sintáticas também apresentam limitações. Dessa maneira, as autoras defendem que a classe de nomes não é dividida apenas em dois tipos: contáveis e massivos, e sim em cinco tipos, que são apresentados em um quadro bastante claro e ilustrativo (GOMES; SANCHEZ-MENDES, 2018, p. 78). Os nomes podem ser: contáveis com átomos naturais, como, por exemplo, gato; contáveis em átomos naturais, como cerca; massivos de substância, como arroz; falsos massivos, como em gente; nomes flexíveis, ex.: chocolate.

A classe dos quantificadores, como abordado pelas autoras, apresenta uma função complexa, que toma outra função como argumento e retorna um valor de verdade. Os quantificadores generalizados não fazem referência a um indivíduo em particular, mas estabelecem uma relação entre o conjunto de indivíduos e o conjunto denotado pelo predicado. São exemplos de quantificadores generalizados: 'ninguém', 'alguém', 'todo mundo'.

Por fim, são apresentadas algumas questões relacionadas à classe dos sintagmas indefinidos. Segundo as autoras, os determinantes apresentam referência fixa e são definidos, enquanto os indefinidos são de referência variável. Diferentemente dos quantificadores, eles podem ser retomados anaforicamente, como nomes próprios. Entretanto, podem apresentar tanto leitura de quantificação existencial quanto leitura de quantificação universal. Dada essas possibilidades de leitura, autores como Kamp (1981) e Heim (1982) defendem que indefinidos não possuem força quantificacional própria, sua função 
é indicar um referente novo. A força quantificacional que o indefinido assume é derivada do contexto, segundo as autoras.

O capítulo 3, reservado ao sintagma verbal, tem como objetivo apresentar as noções semânticas associadas aos predicados verbais, como seleção argumental, tempo, aspecto, modalidade e modo. Sobre a seleção de argumentos, a obra indica o conceito de que cada predicado determina a quantidade de argumentos necessária para sua saturação, além de utilizar critérios semânticos para a seleção desses argumentos. Um exemplo, dado pelas autoras em página 102 é o verbo 'derramar' (GOMES; SANCHEZ-MENDES, 2018, p. 102), que só aceita argumentos líquidos, daí a estranheza de sentenças como "A pedra derramou."

Um assunto interessante que merece destaque na obra é a inclusão do argumento evento como mais um argumento do predicado. Nessa abordagem, um predicado como 'chegar', além de selecionar um argumento agente, também seleciona um argumento abstrato de eventualidade, que indica que 'chegar' é um evento que ocorreu em determinado tempo e lugar.

Na seção sobre tempo verbal, destaca-se o tempo linguístico, que se distingue do tempo cronológico. $\mathrm{O}$ tempo linguístico é dêitico, pois depende do contexto para referenciar o momento. Apresenta uma relação entre o momento da fala (MF) e o momento do evento (ME), denotado pelo verbo. Pela complexidade das relações temporais expressas pelas línguas, Reichenbach (1947) apresentou uma formalização dos tempos verbais, incluindo mais uma referência temporal, o momento de referência (MR). $\mathrm{O}$ momento de referência é capaz de diferenciar, na linha temporal, sentenças como: "Quando minha mãe casou, eu já tinha nascido" (GOMES; SANCHEZ-MENDES, 2018, p. 119). O tempo linguístico, nessa proposta, é dado pela relação entre o momento de referência e o momento da fala. Todos esses conceitos são explorados de forma clara, didática, com diversos exemplos ao longo do capítulo.

$\mathrm{O}$ aspecto verbal é a categoria gramatical que faz relação interna com as eventualidades, indicando se a eventualidade está em andamento ou já foi concluída. O aspecto do verbo pode ser classificado como aspecto lexical ou aspecto gramatical. O lexical indica a natureza dos eventos denotados pelo verbo e o gramatical indica a relação entre o momento 
do evento (ME) e o momento de referência (MR). Quanto ao aspecto gramatical, pode ser caracterizado como perfectivo ou imperfectivo. No aspecto perfectivo, o ME está incluído no $\mathrm{MR}$, nesse caso, o evento teve um fim determinado. No aspecto imperfectivo, $\mathrm{o} M E$ inclui o $\mathrm{MR}$, e o evento não tem um fim determinado, como em "Maria atravessava a rua", à semelhança do que ocorre com os gerúndios em PB (GOMES; SANCHEZ-MENDES, 2018, p. 124). Em relação ao aspecto lexical, a natureza e a acionalidade do verbo é explorada. Vendler (1957) apresentou diferentes classes acionais para indicar a natureza dos eventos denotados pelos verbos. Os predicados são classificados como: accomplishments, achievements, atividades e estado.

A última seção do capítulo 3 é dedicada a apresentar as noções de modo e modalidade. Duas sentenças como as seguintes apresentam força modal distintas: “O João pode descansar no domingo."; 'O João tem que descansar no domingo' (GOMES; SANCHEZ-MENDES, 2018, p. 136). Na proposta semântica, sentenças como essa são formalizadas a partir de mundos possíveis, em que são dadas situações alternativas e hipotéticas. Nessa proposta, modais são quantificadores sobre mundos possíveis. Enquanto poder apresenta quantificação existencial sobre mundos possíveis, ter que denota quantificação universal.

O capítulo 4 tem como objetivo apresentar as questões semânticas que envolvem modificadores como adjetivo ou advérbio. Os adjetivos podem ocorrer na posição predicativa: 'O coelho é branco', ou na posição atributiva: 'O coelho branco fugiu' (GOMES; SANCHEZ-MENDES, 2018, p. 155). Sua função básica é denotar uma qualidade ou classe de elementos a que o indivíduo referido pelo sintagma nominal pertence. $\mathrm{O}$ adjetivo realiza uma operação de intersecção entre conjuntos, seja na posição predicativa seja na atributiva. Pelo fato de o adjetivo possuir características próprias e realizar as mesmas operações nas duas posições em que pode ocorrer, a literatura semântica propõe que a operação realizada pelo adjetivo é uma operação de modificação, que permite que os predicados formem conjunções para se aplicarem ao mesmo argumento.

Há um número considerável de adjetivos que possuem dependência contextual, chamados de adjetivos de grau. Os 
pesquisadores dessa classe defendem que esses possuem propriedades escalares. Dessa forma, adjetivos como 'alto' e 'velho' exigem um grau de comparação dado pelo contexto. Esse grau é medido com base em uma escala com sequência de graus em ordem crescente.

Outra classe de modificadores apresentada nesse capítulo é a dos advérbios. Segundo as autoras, os advérbios realizam operações heterogêneas. Podem modificar a eventualidade, o argumento-evento, o valor de verdade ou a proposição. Os advérbios de modo, tempo e lugar realizam uma operação no domínio verbal, semelhante aos adjetivos no domínio nominal de intersectividade. Os advérbios intensificadores, que são modificadores de grau no domínio verbal, ampliam a dimensão da propriedade modificada. Um exemplo é o advérbio 'muito', que amplia a diferença entre os termos. Em "João correu muito rápido" (GOMES; SANCHEZ-MENDES, 2018, p. 178), a sentença denota que o evento de correr foi rápido, mas em uma escala de rapidez, esse evento está próximo do ponto mais alto da escala. Outros tipos de advérbios são apresentados pelas autoras, como os advérbios de ato de fala, os advérbios quantificadores de frequência e os advérbios modais que fazem uma contribuição à força modal e são dependentes do contexto.

\section{Considerações em relação à obra}

A obra Para Conhecer: Semântica representa uma ferramenta bastante rica, de grande valor tanto para professores dos cursos de Letras no país, que necessitam de um suporte didático para apresentar noções tão complexas da Semântica Formal, quanto para interessados em iniciar suas pesquisas nesse campo tão instigante e ainda carente de pesquisadores. A ênfase na semântica do português brasileiro, apresentando dados e citações de pesquisas em nossa língua, também é um diferencial a ser ressaltado. Além disso, a obra, que faz um panorama geral das pesquisas teóricas e empíricas no campo da semântica, traz um conjunto de citações importantes para a área, desde os clássicos às investigações mais recentes. 


\section{REFERÊNCIAS BIBLIOGRÁFICAS}

CARLSON, G. A unified Analysis of the English Bare Plural. Linguistics and Philosophy, Boulder, Colorado, United States. v. 1, n. 3, p. 339-405, 1977.

CHIERQUIA, G. Reference to Kinds Across Languages. Natural Languages Semantics 6, p. 339-405, 1998.

FREGE, G. Uber Begriff and Gegenstand. Vierteljahresschrift fur Wissenschaftliche Philosophie 16, p. 192-205, 1892. (FREGE, G. Sobre o conceito e o objeto. Lógica e Filosofia da linguagem. Trad. Paulo Alcoforado. São Paulo: Cultrix, 1978.)

GOMES, A. Q.; SANCHEZ-MENDES, L. Para conhecer: Semântica. São Paulo: Contexto, 2018.

HEIM, I. The Semantics of Definite and Indefinite Noun Phrases: 262. Thesis: University of Massachusetts, Amherst, MA, 1982.

KAMP, H. A Theory of Truth and Semantic Representation. In: PORTNER, P.; PARTEE, B. H. Ed. Formal Semantics: The Essential Readings. Ed. Oxford: Blackwell, p. 189-222, 1981.

LINK, G. The Logical Analysis of Plurals and Mass Terms: a Lattice Theoretical Approach. In: BAUERLE, R.; SCHWARSE, C.; VON STECHOW, A. Ed. Meaning, Use and Interpretation of Language. Ed. Berlin: De Gruyter, 1983.

REICHENBACH, H. The Tenses of Verbs. In: MEISTER, J. C.; SCHERNUS, W. Time. From Concept to Narrative Construct: A Reader. Ed. Berlin/New York: The Gruyter, p. 1-12, 2011.

RUSSELL, B. On denoting. Logic and knowledge. Londres: Allen \& Unwin, 1905. p. 39-56. Reimpresso em Zabeeh, Klemke \& Jacobson. Ed. Readings in Semantics. University of Illinois Press, 1974. p.141-158.VENDLER, Z. Verbs and Times. The Philosophical Review, v. 66, n. 2, p. 143-160, 1957. 